\title{
FLOW CHARACTERIZATION OF MULTI-PHASE PARTICULATE SLURRY IN THERMAL POWER PLANTS USING COMPUTATIONAL FLUID DYNAMICS
}

\author{
Om Parkash ${ }^{1, *}$, Rajesh Arora ${ }^{1}$
}

\begin{abstract}
The key issue associated with the thermal power plant is the disposal of ash-water slurry and the process of its transportation is accomplished using long length pipelines. The designing of such pipelines is a vital endeavor of researchers and designers globally. In this perspective, numerical simulation of $42 \mathrm{~mm}$ diameter three-dimensional slurry flow pipeline carrying high concentration of mono-dispersed fine ash particles has been carried out. The study is enunciated by employing Eulerian- Eulerian two-phase model with RNG k- $\varepsilon$ turbulence model with the aim of visualizing and understanding the characteristics of the slurry flow behavior. The coal ash slurry concentration varies between $50 \%$ to $70 \%$ (by weight) for velocity ranges, $1-3 \mathrm{~ms}^{-1}$. The modeling is done using Fluent commercial software with the intention of predicting the characteristics of flow for $300 \mu \mathrm{m}$ particle size. It is observed that pressure drop upsurges non-linearly with solid concentrations and slurry velocity across pipeline. The obtained results of predetermined pressure drop are analytically compared with the experimental results. Moreover, the results are also compared with that of Eulerian-Langrange model using SST K- $\omega$ turbulence model and it is found that RNG k- $\varepsilon$ turbulence model yields more accurate and desirable results.
\end{abstract}

Keywords: 3D CFD, Eulerian-Eulerian Two-Phase Model, Thermal Power Plants, Slurry Concentration, Pressure Drop

\section{INTRODUCTION}

The electrical power generation in thermal power plants utilizes the combustion of coal which results in huge amount of fly and bottom ash. Thus, the transportation of ash-water slurry through long pipeline is a major concern for thermal power plants and other industries. The concentration of coal ash in water determines the extent of damage and deterioration caused to the transportation pipeline. Hence, low ash concentration in slurry results in longer age of pipelines and vice-versa. The transportation of coal ash slurry through pipelines is not only economical and environment friendly but also offers numerous advantages viz. flexible routing, continuous delivery, ease in automation, long distance transportation capability, less manpower/maintenance requirements and low energy consumption etc. Several research experiments are available in the literature in order to evaluate the pressure drops in the horizontal pipelines. But this real-time monitoring is quite complex in nature and involves longer spans for its operation. Recently, investigations of multi-phase fluid flow problems based on Computational Fluid Dynamics (CFD) modeling are increasingly used which offers major advantages of predicting variable range flow conditions and particle profile characteristics in a short span of time. Colwell and Shook [1] carried out an experiment for slurry mixture of sand and polystyrene particle in a horizontal $50 \mathrm{~mm}$ diameter pipeline. They evaluated the velocity and the concentration profiles at three different positions and found the optimal entry lengths for the chosen particle slurry. The effect of Reynolds number and particulate concentration for minute glass beads particle slurry on friction loss is experimentally studied by Turian et al. [2]. It is found that in horizontal pipes the inertial effects are more dominated for non-colloidal flow as compared to the finer non-colloidal flow. Matousek [3] performed a laboratory experiment by using sand water slurry flow in $105 \mathrm{~mm}$ diameter pipeline. The flow characteristic at three different inclinations viz. horizontal, vertical and $-35^{\circ}$ descending pipes are analysed. He observed the flow patterns for fully stratified/suspended flows. Krampa-Morlu et. al. [4] carried out the numerical simulation of courser particles in a vertical pipe line using $k-\varepsilon$ approach and studied the effects of particles size, solid concentrations/viscosities for different slurry flow constraints. Kraft [5] modelled various processes in order to study the characteristics of particulates. Kumar et al. [6] investigated the effects of pressure drops and solid concentrations of bimodal slurries using two different Eulerian two-models (namely two-layer/Karabelas models). Lin and Ebadian [7] carried out the

This paper was recommended for publication in revised form by Regional Editor Balaram Kundu

${ }^{1}$ Department of Mechanical Engineering, Amity University Haryana, Gurgaon, India

*E-mail address: om.mech8@gmail.com

Orcid id: 0000-0001-7080-570X, 0000-0001-9234-4115

Manuscript Received 10 March 2018, Accepted 9 May 2018 
numerical simulation of sand and liquid slurry flow at the entry of horizontal pipeline implementing algebraic slip mixture model. They analysed the growth of several flow constraints at entry section. Chandel et al. [8] studied the pressure drops and rheological features of the fly-ash slurry pipeline. It has been found that the slurry does not show settling behaviour for any flow velocity at all test conditions.

Later, they performed experiments on pilot's plant trial ring for fly-ash slurry with/without additives. They noticed a slight dip in pressure drop by adding an additive i.e., soap solution at high concentration of 60\% [9]. Further, the rheological characteristics are studied at different temperatures using cationic surfactant and counter ion. The addition of the cationic and the counter ions reduces the surface tension with the aim of enhancing the suspension strength in particulates. An increase in the wetting and spreading properties is found which results in low power/water requirements [10]. Senapati et al. [11] investigated the fly/bottom ash slurries to predict the effects of friction on the concentrated slurry. They studied the flow characteristics of the slurry implementing power model laws. Afterwards, the numerical simulations on slush nitrogen flow in $15 \mathrm{~mm}$ diameter, $1.5 \mathrm{~m}$ length horizontal pipe has been carried out for $1.0 \mathrm{~mm}$ particle using $\mathrm{k}-\varepsilon$ turbulence model. It has been concluded that 2-D multiphase model incurs less computational time as compared to 3-D models [12]. Kaushal et al. [13] carried out the numerical simulation of monodispersed glass beads particle at high concentration in $54.9 \mathrm{~mm}$ diameter pipeline using Eulerian and mixture models. It is found that Eulerian model outperforms in terms of predicting pressure drop in the pipeline. Thereafter, they experimented on high concentration fly ash slurry using pilot plant test loop in order to estimate its rheological behaviour. The optimum concentrations of fly-ash slurries on the basis of specific energy consumptions is found to be $65 \%$ (by weight) [14] The numerical investigation on the sand-water slurry flow through pipeline has been carried out by Nabil et al. [15]. They considered three different particle sizes of $0.2,0.7$ and $1.4 \mathrm{~mm}$ for 0.5 to $5 \mathrm{~m} / \mathrm{sec}$ velocity range and found that the irregularities goes up with particle's size due to gravitational effect. Silva et al. [16] studied the settling behaviour of slurry flow and investigated the effects of flow velocity on it. Gopaliya and Kaushal [17] analysed the effects of grain sizes on the slurry flow characteristics in horizontal pipelines implementing RNG k- $\varepsilon$ turbulence model. Pani et al. [18] studied the rheological behaviour of coal ash slurry and investigated the effects of chosen additives on it. Assefa and Kaushal [19] carried the experimental investigations on bottom/fly-ash slurry with/without additions of fly/bottom ash in order to evaluate its rheological behaviour. The extensive drop in the yield stress and the viscosity is observed with $30 \%$ mixing proportions to the fly ash slurry whereas the aforesaid parameters rapidly shoot up with $40 \%$ of mixing proportions at all solid concentrations. Afterwards, the CFD modeling of sand water slurry in a horizontal pipeline has been accomplished using Eulerian two-phase model by Swamy et al. [20]. The simulated results are verified with experimental data and heterogeneous flow regimes are found for larger particle sizes. Wu et al [21] established a simulation model in order to investigate the flow characteristics of the CGF slurry in the pipeline. The CGF mixture consists of cement, coal gangues/fly-ash and liquid. Messa and Malavasi [22] presented a novel two- fluid model in order to simulate the liquid solid slurry in horizontal pipeline. They have chosen 50-200mm pipe diameter for 90-640 $\mu \mathrm{m}$ particle size. Furthermore, the experimental and numerical simulation of sand water slurry flow in $263 \mathrm{~mm}$ diameter pipe at different velocities is done using Eulerian multiphase renormalization group $k-\varepsilon$ turbulence model. They noticed that the pressure gradient is more dominant on the efflux concentrations. The velocity profile is observed as symmetric/ asymmetric for fine/coarse particle concentrations [23]. Ofei and Ismail [24] carried out the numerical simulation of particulate liquid slurry in a horizontal pipe using Eulerian-Eulerian twophase model with $k-\varepsilon$ turbulence model. They have chosen different particle sizes ranging $90-270 \mu \mathrm{m}$ for $10-40 \%$ solid concentrations. It is noticed that frictional pressure loss goes down as the particle size increases for predetermined volume fractions. Peng and Cao [25] utilized Eulerian Lagrangian method to investigate the flow characteristics in bend pipe. They studied the variations of different parameters on the slurry flow. The experimental investigations on bi modal slurry comprising of fly ash and silica particles has been carried out by Kaushal et. al. [26]. The study is carried out for six silica sand/fly ash ratios (namely100/0, 90/10, 80/20, 70/30, 60/40 and 0/100). The flow velocity ranges 1.78-3.56 m/sec for 75-450 $\mu \mathrm{m}$ mean diameter particle sizes at efflux concentrations of $8.82 \%$ and $16.28 \%$. The lower values of pressure drop for bi-modal slurry is observed as compared with the mono disperse silica particle. Assefa and Kaushal [27] proposed a novel empirical model to investigate the viscosity profile for multi size particulates Bingham slurry at higher values of concentration ( $>50 \%$, by weight). The proposed model utilizes non-linear least square curve fitting and optimization method for solid volume fractions, particle size and uniformity coefficient as input parameters. Melorie and Kaushal [28] experimentally studied the impact of chemical additives on rheological characteristics in an iron ore slurry having concentration range, 18.8-25.8\%. They found that the addition of hydrated lime increases yield stress at different solid concentrations. Naveh et al [29] employed various turbulence models in order to see the pressure drops for diluted slurry in horizontal pipes. They noticed that the pressure drop is 
a sturdy function of Archemede's number. Singh et al. [30] predicted the flow characteristics of bottom ash and water slurry flow in a $50 \mathrm{~mm}$ diameter horizontal pipeline for wide velocity ranges using Eulerian- Lagrange two-phase approach with SST K- $\omega$ turbulence model based on CFD modelling. The simulated results are also compared with the experimental ones. It is found that the pressure drops increase non-linearly with increase in velocity and solid concentrations. The computational fluid dynamic analysis carried out in the present study can be further enhanced on the characterisation and profile analysis of heat transfer characteristics of Nano fluids. This study will be very helpful in setting up of practical systems with the help of Nano particles [31-72].

In the literature, many experimental and numerical studies are found on the parametric designing of high concentration slurry pipeline for fly ash, bottom ash, glass beads and sand etc. However, it is observed that the experimental determination of velocity, pressure drop and concentration profile at various pipeline locations is very rigorous and time-consuming process. Henceforth, computational fluid dynamics possess abundant scope and competence for evaluating aforementioned parameters at any cross-section of the pipeline. In this paper, an attempt has been made to develop concentration, velocity and pressure drop profiles for $300 \mu \mathrm{m}$ particle size employing Eulerian- Eulerian two-phase model with RNG k- $\varepsilon$ approach. The modeling of $42 \mathrm{~mm}$ diameter pipeline has been carried out for solid concentration ranging $50 \%$ to $70 \%$ (by weight) with wide velocity span of $1-3 \mathrm{~m} / \mathrm{s}$. The validation of the numerical simulation is done by comparing the simulated outcomes with the experimental results. The results are further compared with that of Eulerian-Langrange model using SST K- $\omega$ turbulence model and it is found that the proposed model gives more precise and accurate results.

\section{MATHEMATICAL MODEL}

In this paper, an efficient Eulerian-Eulerian multi-phase model is adopted for numerical simulation. The following governing equations are used for the turbulent flow of fly ash particles in the Newtonian fluid.

\section{Eulerian Model}

This model comprises of most complex equations of multiphase modelling in FLUENT software. In Eulerian model, the slurry is assumed to be comprised of solid and liquid phases. The concentrations of the two phases are assumed to be $\alpha_{\mathrm{s}}$ and $\alpha_{\mathrm{f}}$ for $\alpha_{\mathrm{s}}+\alpha_{\mathrm{f}}=1$. It is based on solving a set of continuity/momentum equations for every phase viz. solid/liquid. In the present study, granular flows have been undertaken comprised of fluid/solid intermixing whose modelling can be achieved by appropriate constraints of interphase exchange and pressure coefficients. Moreover, the characteristics of the flow has been derived with the applications of kinetic theory. The forces acting on each particle in the slurry comprises of:

1. Static/solid pressure gradients, $\nabla \mathrm{P} / \nabla \mathrm{P}$ s.

2. Forces due to the difference in velocities of two phases, $K_{s f}\left(\vec{v}_{s}-\vec{v}_{f}\right)$

3. Viscous and body forces, $\nabla \cdot \overline{\overline{\tau_{f}}}$ and $\rho \overrightarrow{\mathrm{g}}$, where $\overline{\overline{\tau_{f}}}$ represents the stress tensor of fluid, $\rho$ denotes the mass density and g is gravitational acceleration.

4. Lift/virtual mass forces. The coefficient of virtual mass/ lift forces, $\mathrm{C}_{\mathrm{L}} / \mathrm{C}_{\mathrm{vm}}$ are assumed to be 0.5.

5. The particles in the analysis are assumed to be fluid in nature.

\section{Governing Equations}

The following governing equations are used for the turbulent flow of fly ash particles in the Newtonian fluid. The continuity/momentum equation for each phase is defined as [14]:

\section{Continuity Equation}

$$
\nabla \cdot\left(\alpha_{\mathrm{t}} \rho_{\mathrm{t}} \overrightarrow{\mathrm{v}}_{\mathrm{t}}\right)=0
$$

Here, $\mathrm{t}$ can be considered as $\mathrm{f}$ or $\mathrm{s}$.

\section{Momentum Equations for fluid and solid phases}

For Fluids: 


$$
\nabla \cdot\left(\alpha_{f} \rho_{f} \vec{v}_{f} \vec{v}_{f}\right)=-\alpha_{f} \nabla P+\nabla \cdot\left(\overline{\overline{\tau_{f}}}+\overline{\overline{\tau_{t, f}}}\right)+\alpha_{f} \rho_{f} \vec{g}+K_{s f}\left(\vec{v}_{s}-\vec{v}_{f}\right)+C_{v m} \alpha_{s} \rho_{f}\left(\vec{v}_{s} \cdot \nabla \vec{v}_{s}-\vec{v}_{f} \cdot \nabla \vec{v}_{f}\right)+C_{L} \alpha_{s} \rho_{f}\left(\vec{v}_{f}-\vec{v}_{s}\right) \times\left(\nabla \times \vec{v}_{f}\right)
$$

For Solids:

$$
\nabla \cdot\left(\alpha_{s} \rho_{s} \vec{v}_{s} \vec{v}_{s}\right)=-\alpha_{s} \nabla P-\nabla P_{s}+\nabla \cdot\left(\overline{\overline{\tau_{s}}}+\overline{\overline{\tau_{t, f}}}\right)+\alpha_{s} \rho_{s} \vec{g}+K_{f s}\left(\vec{v}_{f}-\vec{v}_{s}\right)+C_{v m} \alpha_{s} \rho_{f}\left(\vec{v}_{f} \cdot \nabla \vec{v}_{f}-\vec{v}_{s} \cdot \nabla \vec{v}_{s}\right)+C_{L} \alpha_{s} \rho_{f}\left(\vec{v}_{s}-\vec{v}_{f}\right) \times\left(\nabla \times \vec{v}_{f}\right)
$$

where,

$$
\begin{gathered}
\overline{\overline{\tau_{s}}}=\alpha_{s} \mu_{s}\left(\nabla \vec{v}_{s}+\nabla \vec{v}_{s}^{t r}\right)+\alpha_{s}\left(\lambda_{s}-\frac{2}{3} \mu_{s}\right) \nabla \cdot \vec{v}_{s} \overline{\bar{I}} \\
\overline{\overline{\tau_{f}}}=\alpha_{f} \mu_{f}\left(\nabla \vec{v}_{f}+\nabla \vec{v}_{f}^{t r}\right) \\
\lambda_{s}=\frac{4}{3} \alpha_{s} \rho_{s} d_{s} g_{o, s s}\left(1+e_{s s}\right)\left(\frac{\Theta_{s}}{\pi}\right)^{\frac{1}{2}}
\end{gathered}
$$

$d_{s}$ is the diameter of the particles which is taken as $300 \mu \mathrm{m}$ in the present study.

\section{Solid Shear Viscosity}

The shear viscosity, $\mu_{\mathrm{s}}$ is given as:

$$
\mu_{s}=\mu_{s, c o l}+\mu_{s, k i n}+\mu_{s, f r}
$$

where,

$$
\mu_{s, c o l}=\frac{4}{5} \alpha_{s} \rho_{s} d_{s} g_{o, s s}\left(1+e_{s s}\right)\left(\frac{\Theta_{s}}{\pi}\right)^{\frac{1}{2}}
$$

where,

$$
\begin{gathered}
\Theta_{s}=-\frac{K \Theta_{s}}{\gamma} \frac{\partial \Theta_{s}}{\partial n}+\frac{\sqrt{3} \Pi \Phi \rho_{s} \alpha_{s} v_{s}^{2} g_{o, s s} \Theta_{s}^{3 / 2}}{6 \alpha_{s, \max } \gamma} \\
\mu_{s, f r}=\frac{P_{s} \sin \varphi}{2 \sqrt{I_{2 D}}} \\
\mu_{s, k i n}=\frac{\alpha_{s} d_{s} \rho_{s} \sqrt{\Theta_{s} \pi}}{6\left(3-e_{s s}\right)}\left[1+\frac{2}{5}\left(1+e_{s s}\right)\left(3 \mathrm{e}_{s s}-1\right) \alpha_{s} g_{o, s s}\right]
\end{gathered}
$$

The inter-phasial momentum exchange coefficient, $\mathrm{K}_{\mathrm{sf}}$ is given as:

$$
K_{s f}=K_{f s}=\frac{3}{4} \frac{\alpha_{s} \alpha_{f} \rho_{f}}{V_{r, s}^{2} d_{s}} C_{D}\left(\frac{\operatorname{Re}_{s}}{V_{r, s}}\right)\left|\vec{v}_{s}-\vec{v}_{f}\right|
$$

The drag coefficient, $\mathrm{C}_{\mathrm{D}}$ is given as: 


$$
C_{D}=\left[0.63+4.8\left(\frac{\mathrm{Re}_{s}}{V_{r, s}}\right)^{\frac{-1}{2}}\right]^{2}
$$

\section{WALL FUNCTION}

The gradient quantities are very large in number near the wall area which requires fine grid near the wall. Therefore, the simulation software needs more memory, faster processor and large computation time in order to simplify complex equations. The standard wall function projected by Launder and Spalding has been employed in the current work. The chosen wall function provides more precise and meticulous results for both fluid and liquid phases using Eulerian two-phase model.

\section{Mathematical Solutions}

\section{Geometrical Considerations}

The computation grid for straight horizontal pipe of length $3.8 \mathrm{~m}$ and $42 \mathrm{~mm}$ diameter is created in ICEM CFD using software ANSYS 16.

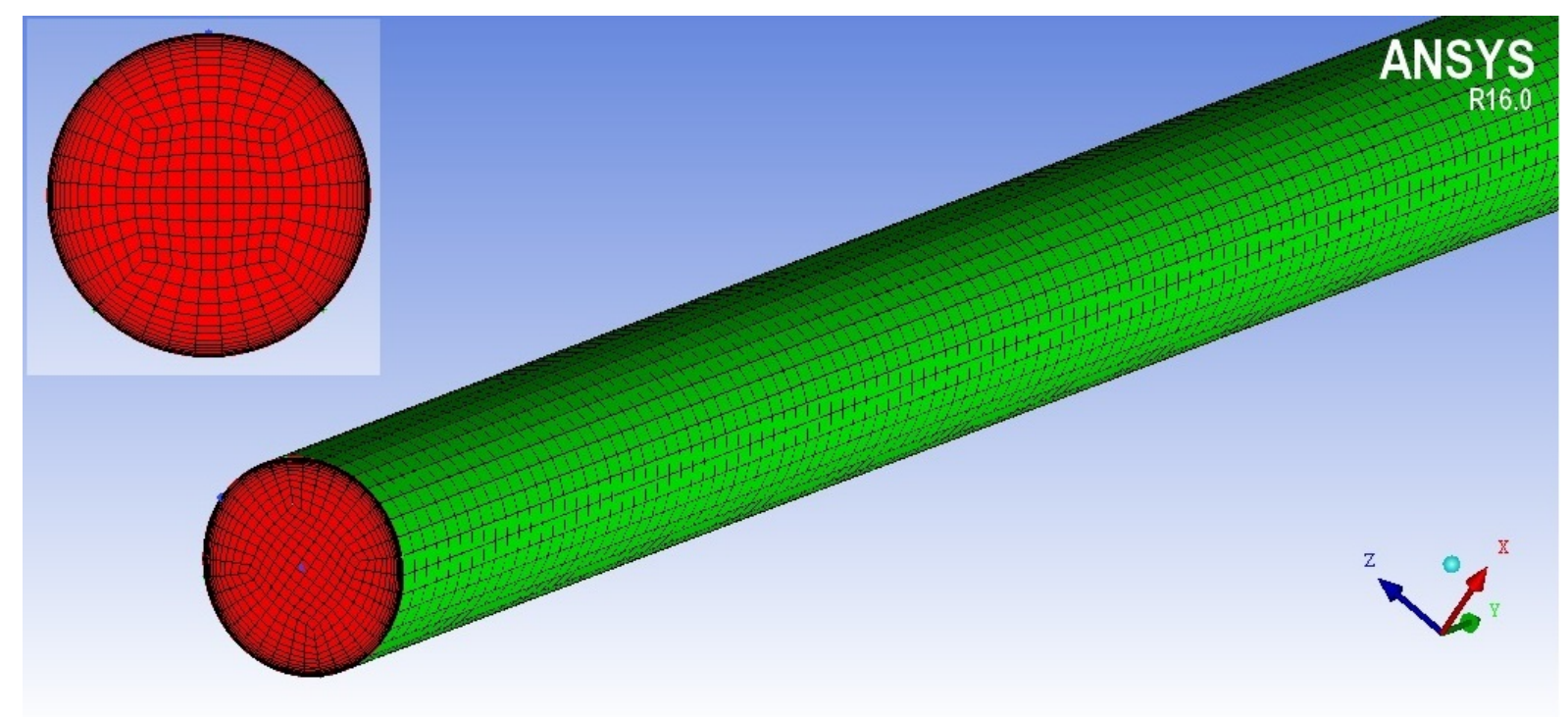

Figure 1. Mesh geometry

The length of the pipeline in the present study is more than 50 diameters, which is sufficiently long for fully developed flow. In order to improve the wall function performance, the grid is refined near the wall of the pipeline as shown in Figure 1. Consequently, the dimensionless adjacent cell distance from the wall, $\mathrm{y}^{+}$becomes 30 and thereby $\mathrm{y}^{+}=30$ condition, has also been pacified with the refinement of the grid. The grid independent test is carried out for pipe geometry containing 4.12 Lakhs; 5.49 Lakhs; 6.16 Lakhs and 7.30 Lakhs, quad and hexahedral cells. It is seen that identical results obtained for 5.49 Lakhs; 6.16 Lakhs and 7.30 Lakhs cells. Hence, a grid with 5.49 Lakhs cells is chosen for computations as obtained in Fig. 1.

\section{BOUNDARY CONDITIONS}

The pipeline geometry comprises of three bounded faces viz. inlet, outlet and wall boundaries to accomplish fluid domain calculations. The velocity inlet, pressure outlet and no slip condition is considered for fluid flow area computations. The conditions for inlet/outlet boundaries are applied to the fluid domain at particular velocity and volume fractions. The assumption of no slip conditions has been considered at the wall. Additionally, the roughness constant of the wall is assumed as 0.5 . 


\section{Strategy towards Converging solutions}

In order to simplify momentum, turbulence kinetic energy and fluid flow dissipation rates equation, a second order windward structure is utilized. This arrangement offers high precision, fidelity and converging of the solutions. The converging condition works on the basis of residual value of various constraints viz. mass, turbulent kinetic, velocity, dissipation energy and volume fractions. In the current study, the value is reset to 0.001 time the initial residual values for every constraint. With the aim to couple the pressure and velocity of the fluid flows, SIMPLE algorithm has been adopted. The other solution strategy includes the under relaxation factors of pressure - 0.7 , momentum -0.5 , volume fraction -0.5 , turbulent viscosity -0.8 , turbulent kinetic/dissipation energies as 0.8 . This converges the non-linear equations into linear ones.

\section{MODELING RESULTS \\ Concentration Distribution}

The results predicted by Eulerian-Eulerian two-phase model at different velocities and solid concentrations have been plotted in the Figs 2-8. It has been found that as the flow velocity increases from $1 \mathrm{~m} / \mathrm{sec}$ to $3 \mathrm{~m} / \mathrm{sec}$, the particles interaction with the wall also goes up. The numerical simulation process has been accomplished for fly ash concentrations ranging 50\% to 70\% (by weight) in flow velocities varying between $1 \mathrm{~m} / \mathrm{sec}$ and $3 \mathrm{~m} / \mathrm{sec}$. The results are plotted for the vertical plane at the outlet section of the pipeline. It is clearly shown that the higher fly ash concentrations region is lying near the bottom of the pipe because of gravitation effects, as illustrated in Figs 2-3. It is also found that the fly ash particles have a tendency to settle down near the lower portion of the pipeline at low velocities. Besides, with the increase in flow velocities, the suspension stability of the particles also goes up, causing more interaction with the wall of the pipeline. One can also notice the decrease in fly ash concentrations from bottom to top zone of the pipeline, as shown in the Figs 5-8.
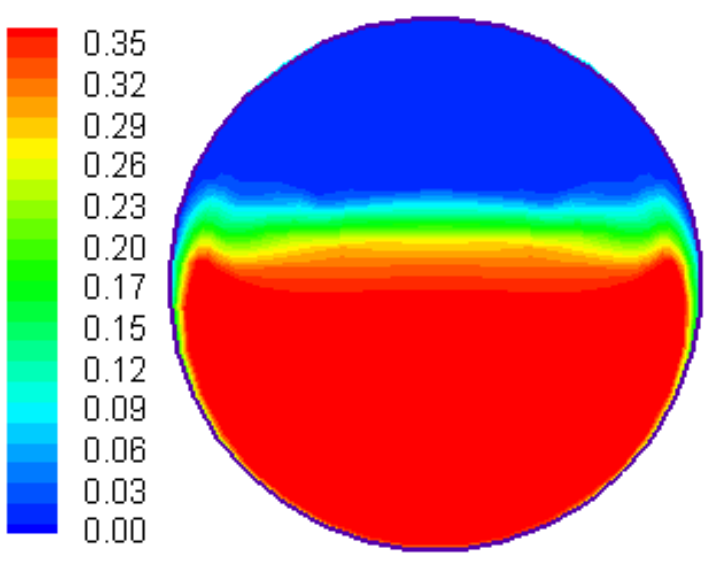

(a)

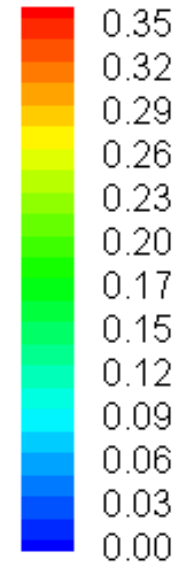

0.00

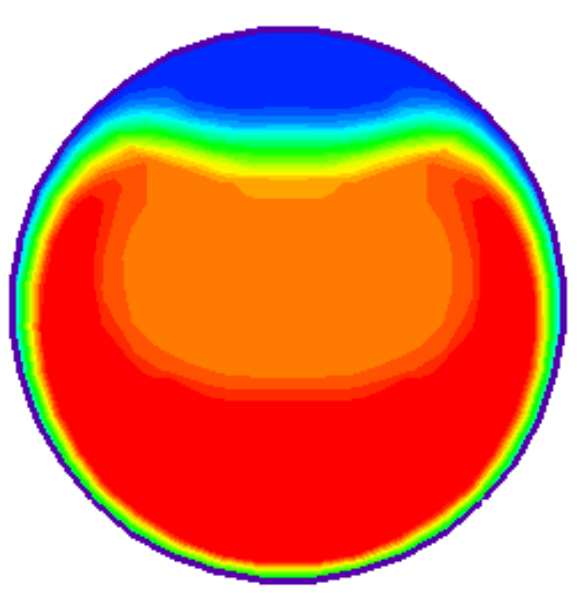

(b)

Figure 2. Fly Ash concentration distribution predicted at $C_{w}=50 \%$ (a) $V_{m}=1 \mathrm{~ms}^{-1}$ and (b) $V_{m}=3 \mathrm{~ms}^{-1}$.
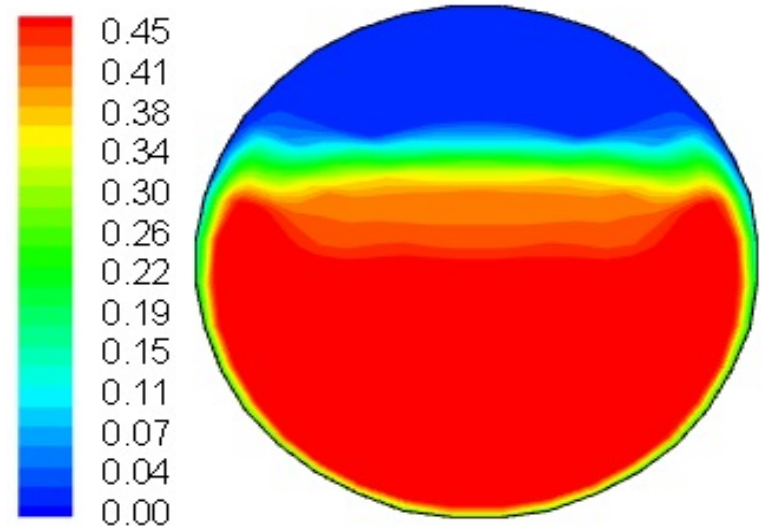

(a)
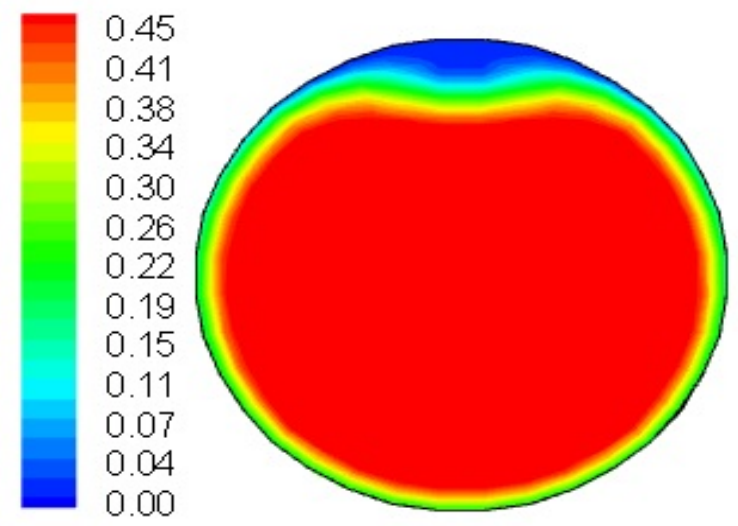

(b)

Figure 3. Fly Ash concentration distribution predicted at $C_{w}=60 \%$ (a) $V_{m}=1 \mathrm{~ms}^{-1}$ and (b) $V_{m}=3 \mathrm{~ms}^{-1}$ 


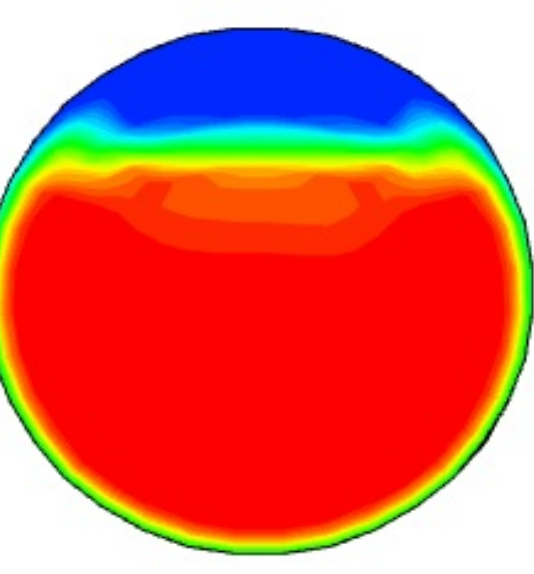

(a)

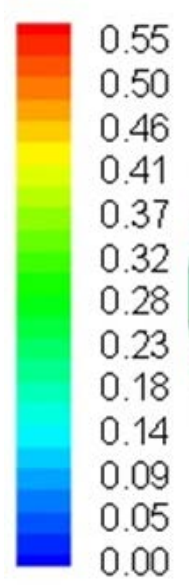

0.00

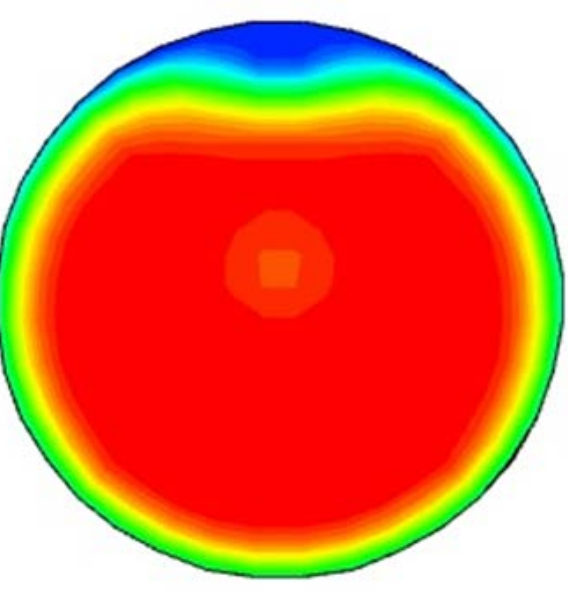

(b)

Figure 4. Fly Ash concentration distribution predicted at $C_{w}=70 \%$ (a) $V_{m}=1 \mathrm{~ms}^{-1}$ and (b) $V_{m}=3 \mathrm{~ms}^{-1}$

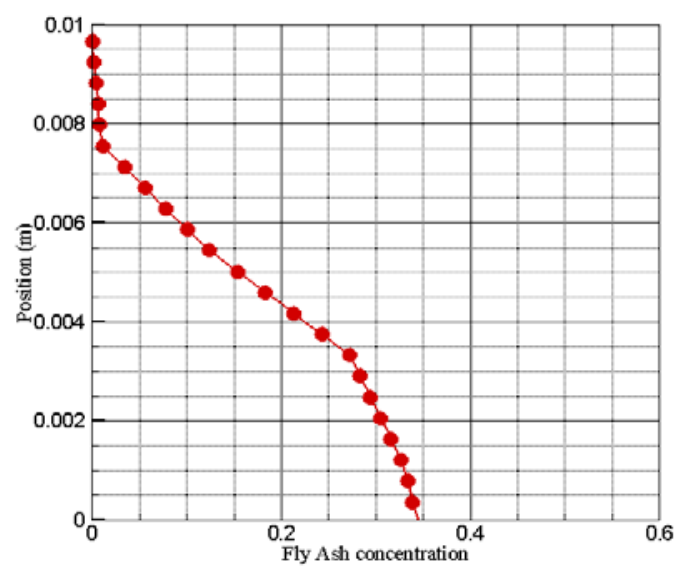

(a)

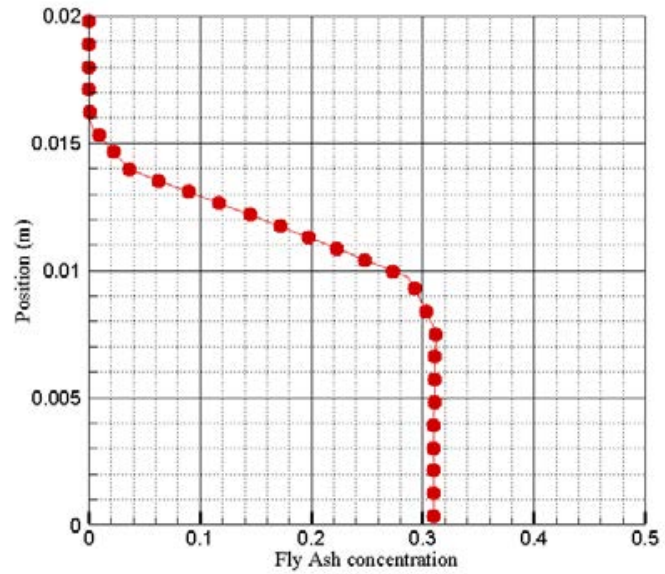

(b)

Figure 5. Fly Ash concentration distribution predicted at $C_{w}=50 \%$ (a) $V_{m}=1 \mathrm{~ms}^{-1}$ and (b) $V_{m}=3 \mathrm{~ms}^{-1}$

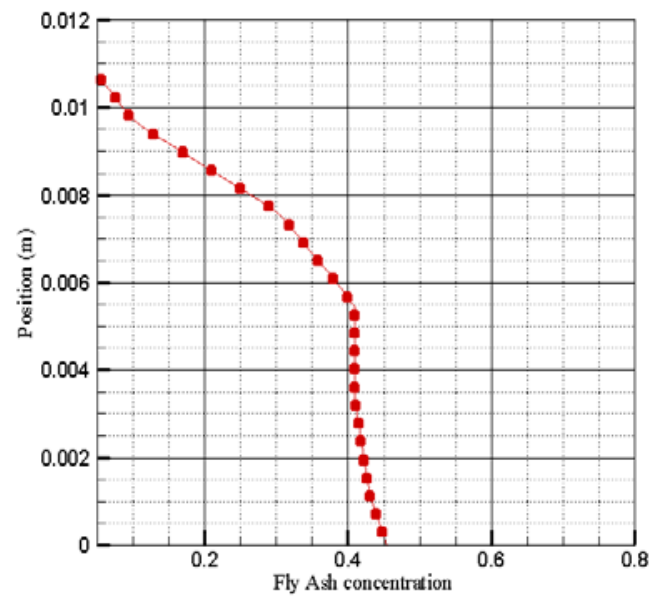

(a)

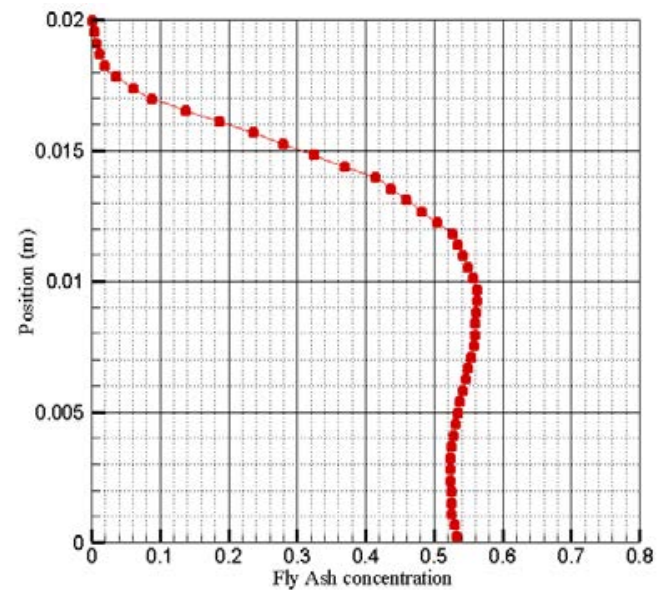

(b)

Figure 6. Fly Ash concentration distribution predicted at $C_{w}=60 \%$ (a) $V_{m}=1 \mathrm{~ms}^{-1}$ and (b) $V_{m}=3 \mathrm{~ms}^{-1}$ 


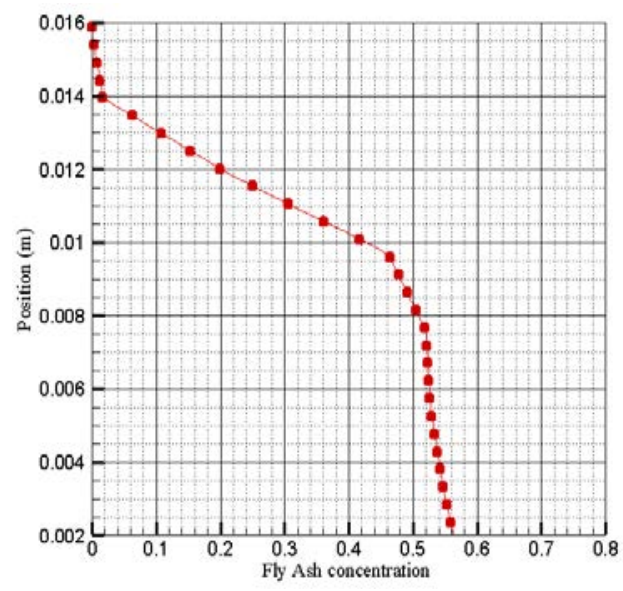

(a)

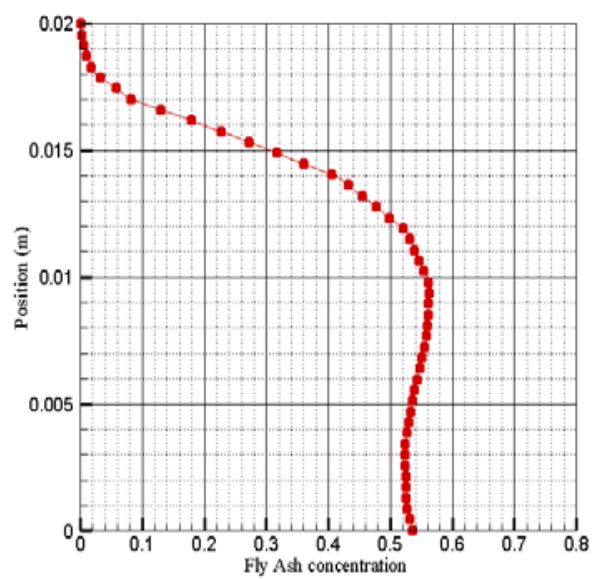

(b)

Figure 7. Fly Ash concentration distribution predicted at $C_{w}=70 \%$ (a) $V_{m}=1 \mathrm{~ms}^{-1}$ and (b) $V_{m}=3 \mathrm{~ms}^{-1}$

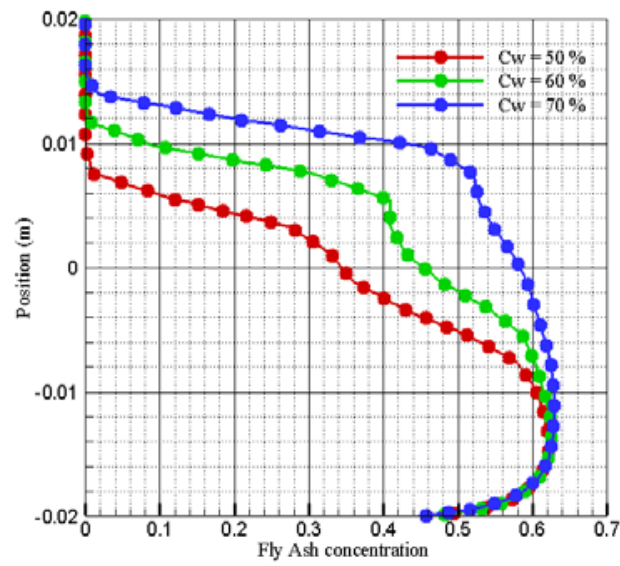

(a)

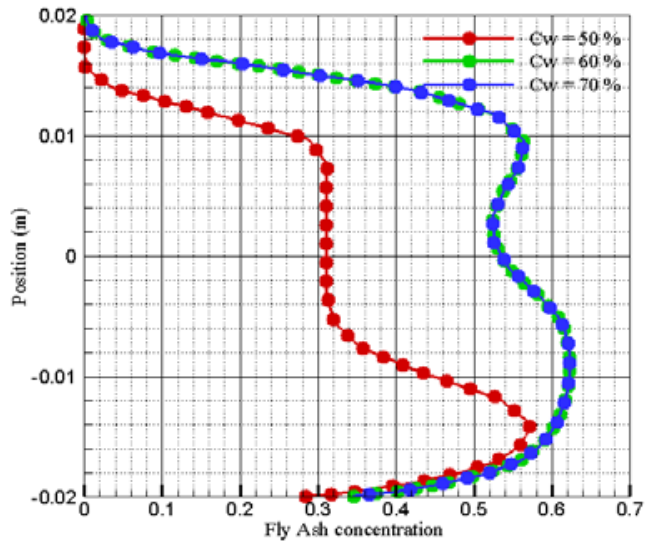

(b)

Figure 8. Different fly ash concentration profile at mean flow velocity of (a) $1 \mathrm{~m} / \mathrm{s}$ and (b) $3 \mathrm{~m} / \mathrm{s}$

\section{VELOCITY DISTRIBUTION OF SOLID PHASE}

Figs 9-15 shows the velocity contours and profiles for the fly ash concentrations between 50-70 \% (by weight) at mean slurry velocities of 1-3 m/s. The symmetrical nature of vertical velocity profile depends upon the mean flow velocity and solid concentrations. It is seen that the velocity profile is asymmetric in nature at low velocities and concentrations. This is due to the high shear force of the particulate with the pipeline wall and lack of turbulence mixing between fly ash and water. As the solid concentration and flow velocity increases, the velocity profile becomes symmetric in nature which is the result of increased turbulent mixing.
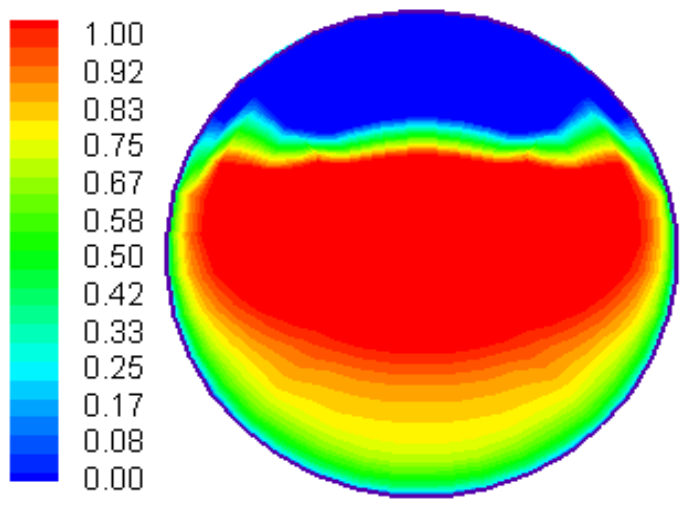

(a)

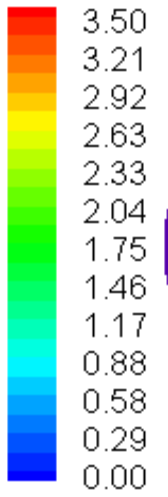

0.00

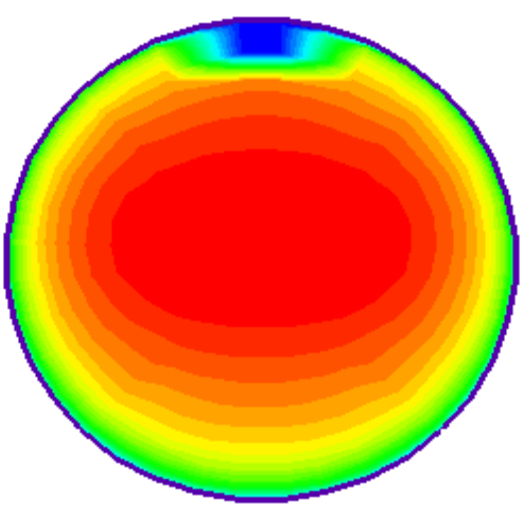

(b)

Figure 9. Velocity distribution predicted at $C_{w}=50 \%$ (a) $V_{m}=1 \mathrm{~ms}^{-1}$ and (b) $V_{m}=3 \mathrm{~ms}^{-1}$ 

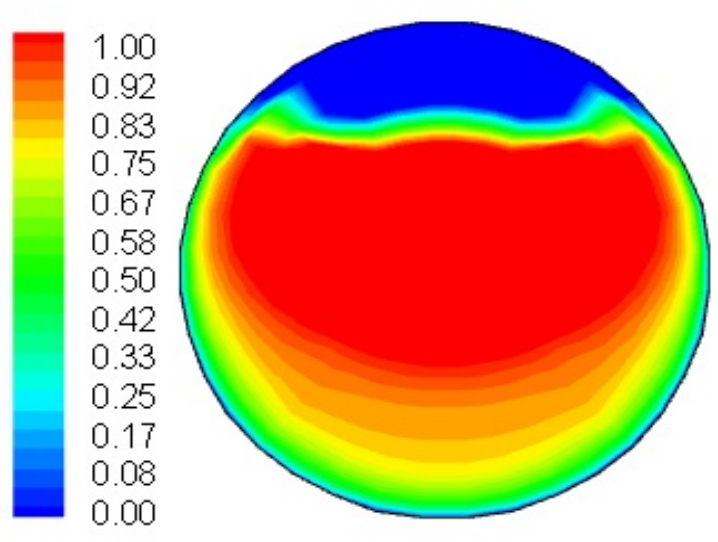

(a)

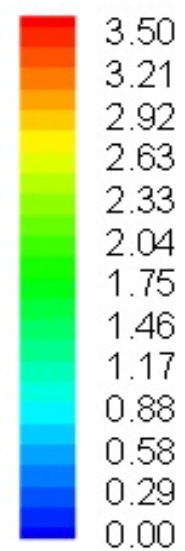

0.00

Figure 10. Velocity distribution predicted at $C_{w}=60 \%$ (a) $V_{m}=1 \mathrm{~ms}^{-1}$ and (b) $V_{m}=3 \mathrm{~ms}^{-1}$

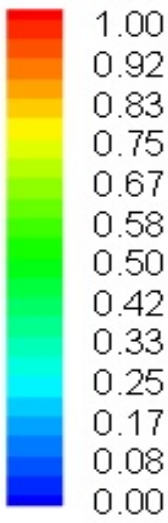

1.00
0.92
0.83
0.75
0.67
0.58
0.50
0.42
0.33
0.25
0.17
0.08
0.00

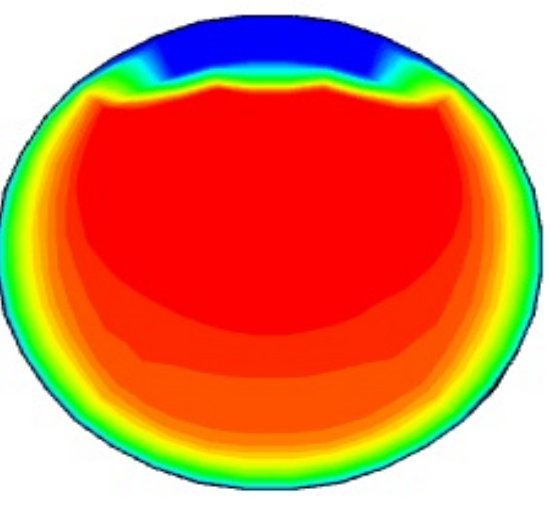

(a)

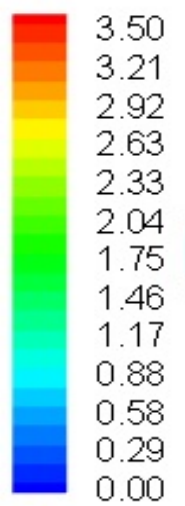

0.00

Figure 11. Velocity distribution predicted at $C_{w}=70 \%$ (a) $V_{m}=1 \mathrm{~ms}^{-1}$ and (b) $V_{m}=3 \mathrm{~ms}^{-1}$

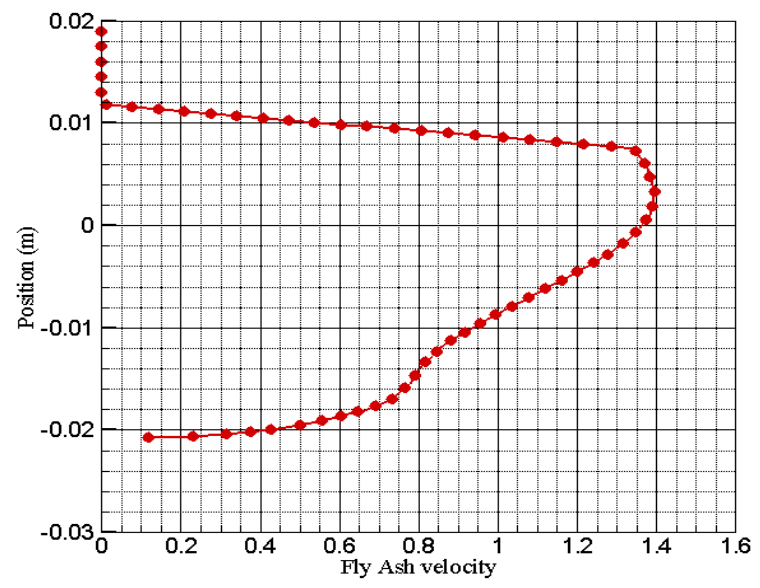

(a)

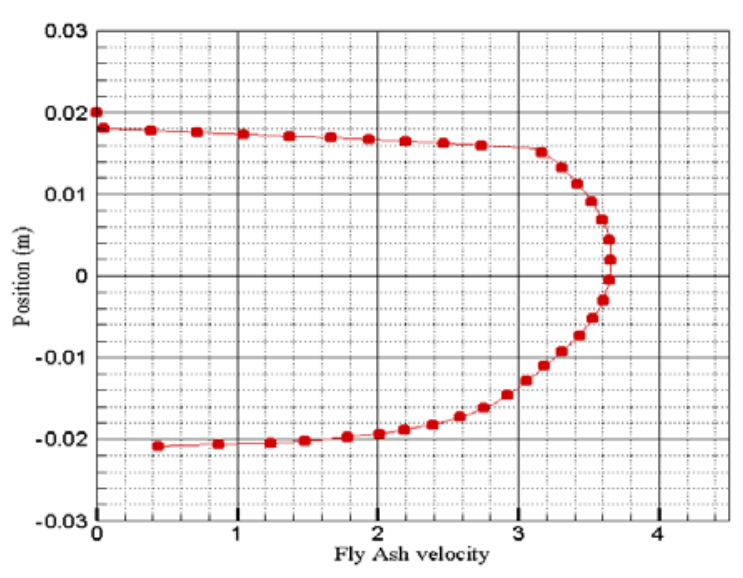

(b)

Figure 12. Vertical velocity profile of fly ash concentration at $C_{w}=50 \%$ (a) $V_{m}=1 \mathrm{~ms}^{-1}$ and (b) $V_{m}=3 \mathrm{~ms}^{-1}$ 


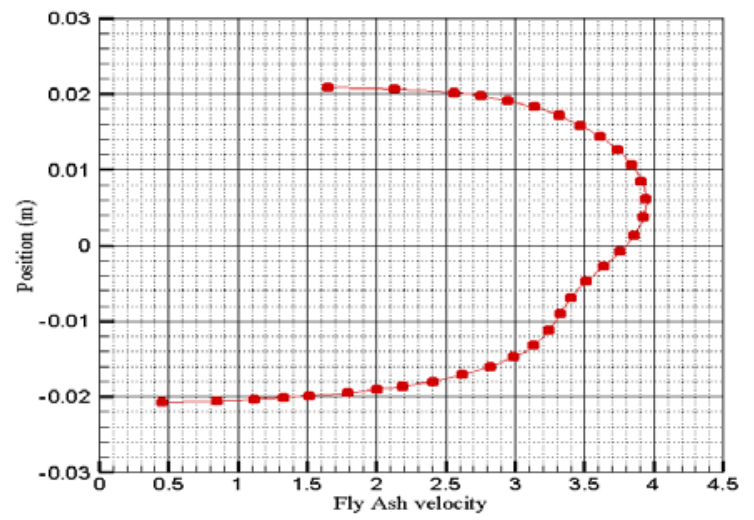

(a)

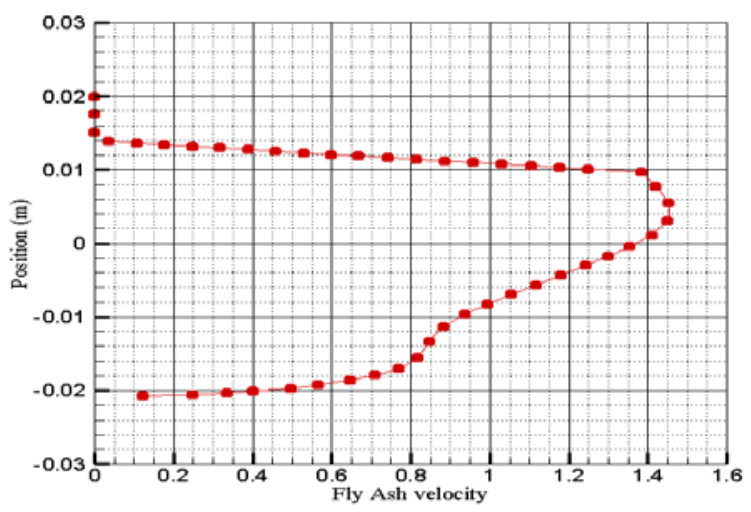

(b)

Figure 13. Vertical velocity profile of fly ash concentration at $C_{w}=60 \%$ (a) $V_{m}=1 m^{-1}$ and (b) $V_{m}=3 \mathrm{~ms}^{-1}$

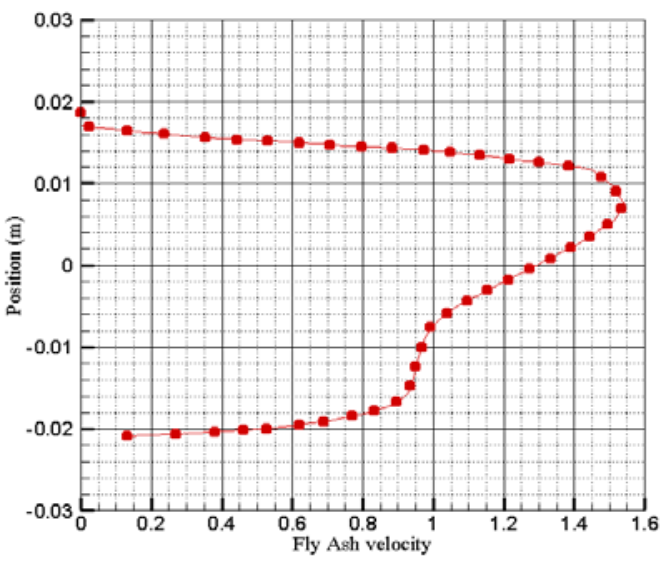

(a)

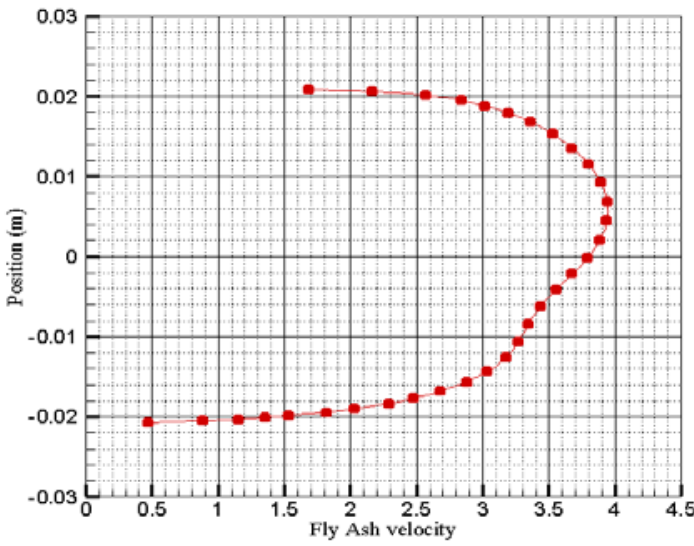

(b)

Figure 14. Vertical velocity profile of fly ash concentration at $C_{w}=70 \%$ (a) $V_{m}=1 \mathrm{~ms}^{-1}$ and (b) $V_{m}=3 \mathrm{~ms}^{-1}$

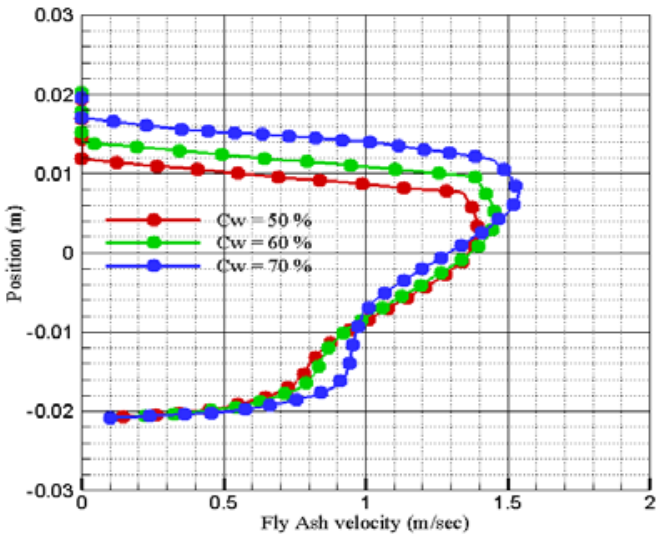

(a)

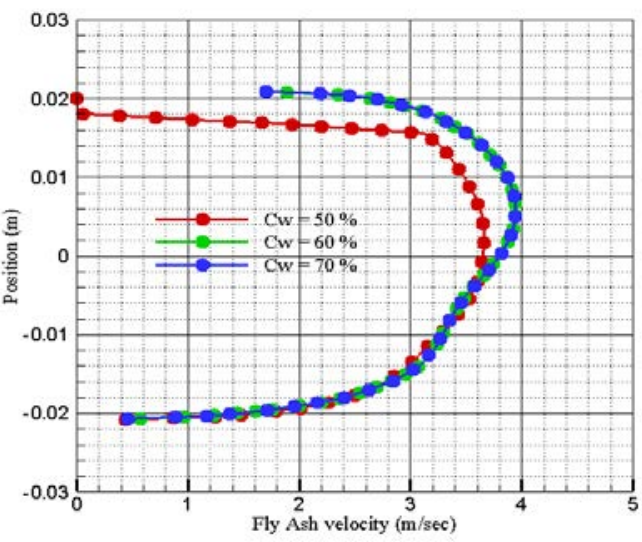

(b)

Figure 15. Vertical velocity profile at different fly ash concentrations at (a) $V_{m}=1 \mathrm{~ms}^{-1}$ and (b) $V_{m}=3 \mathrm{~ms}^{-1}$

\section{PRESSURE DROP}

The variations of pressure drop with different slurry velocities i.e., $1-3 \mathrm{~m} / \mathrm{s}$ for a range of $50-70 \%$ (by weight) solid concentration are shown in Fig. 16. The simulation has been carried out for span of pressure drop from $0-160 \mathrm{~m}$ of water column ( $\mathrm{mWc} / 100 \mathrm{~m}$ length of pipe) over large variations of flow parameters. The variations in the slurry velocities are taken as $1-3 \mathrm{~m} / \mathrm{s}$ for $50 \%$ to $70 \%$ solid concentrations of fly ash. It can be perceived from Fig. 10 that as velocity increases, pressure drop also goes up for concentration level. Moreover, at higher velocities, the rate of inclination is observed to be much higher as compared to the other one. The rate of 
enhancement of pressure drop is more prominent at higher solid concentrations and linearly varies with flow profile of the slurry in the pipeline. The values of pressure drop for $50 \%, 60 \%$ and $70 \%$ solid concentrations at $1 \mathrm{~m} / \mathrm{s}$ slurry velocity are observed as $4.5,5.9$ and $56 \mathrm{mWc}$ per $100 \mathrm{~m}$ length of pipe respectively. On the other hand, the pressure drop values at slurry velocity of $3 \mathrm{~m} / \mathrm{s}$ are found to be 37.3, 40 and $147.8 \mathrm{mWc}$ per $100 \mathrm{~m}$ length of pipe. Moreover, the obtained results are in covenant with that of Chandel et. al. (2009) and Singh et. al. (2017).

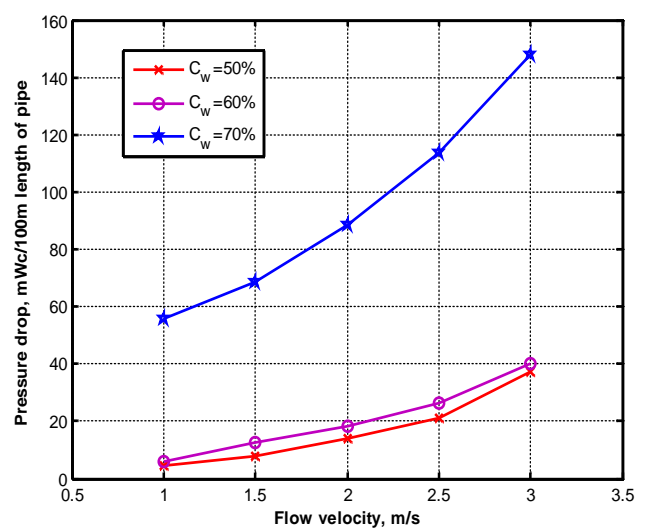

Figure 16. Variations of pressure drop with flow velocities at different values of concentrations

\section{SLIP VELOCITY}

Figs 17 (a-c) shows the variations of the slurry slip velocity across the vertical plane (i.e., Y-Z plane) of the pipeline. It is noticed that the water flows with higher velocity compared to fly ash particles near the bottom zone of the pipe line. It is also experienced that slip velocities initially increase with the elevation from the bottommost portion of the pipeline and reduces near the top zone. Moreover, the slurry slip velocities goes up with solid concentration and mean flow velocity at bottom zone of the pipeline. At lower concentrations, the effects of flow velocities over slip velocities are more prominent.

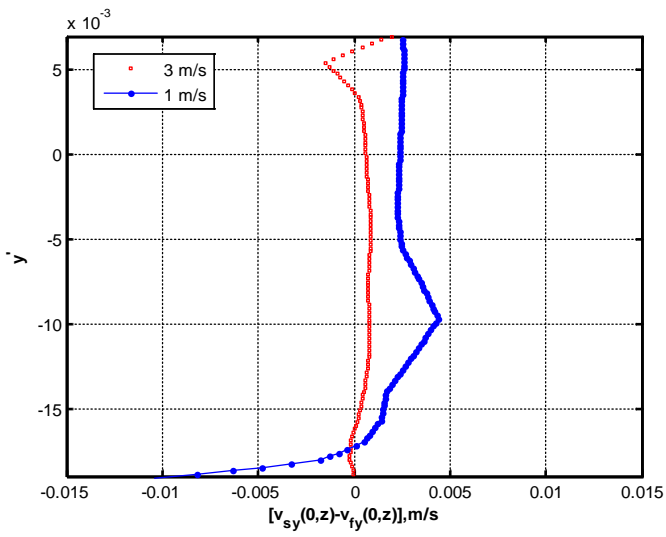

(a)

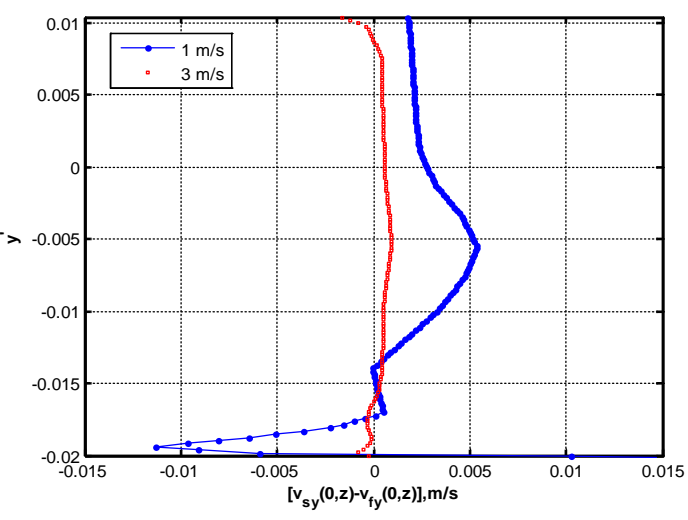

(b)

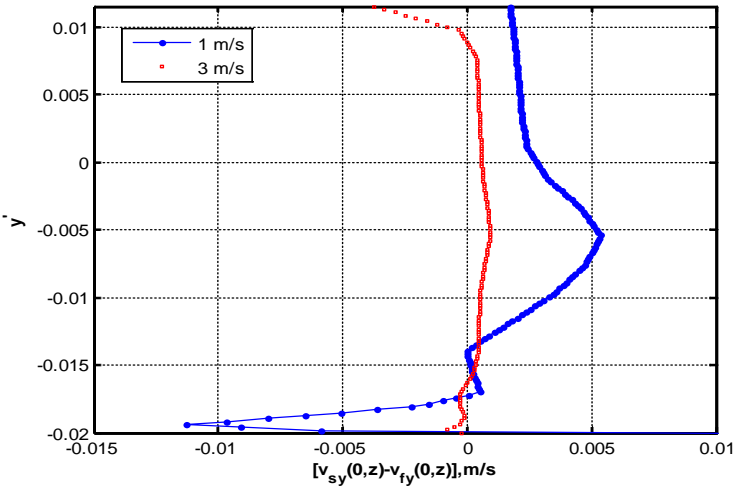

(c)

Figure 17. Slip velocity $\left[\mathrm{v}_{\mathrm{sy}}(\mathrm{o}, \mathrm{z})-\mathrm{v}_{\mathrm{fy}}(0, \mathrm{y})\right]$ distribution predicted by Eulerian Model at (a) $\mathrm{C}_{\mathrm{w}}=50 \%$, (b) $\mathrm{C}_{\mathrm{w}}=60 \%$, and (c) $\mathrm{C}_{\mathrm{w}}=70 \%$ 


\section{VALIDATION OF THE STUDY}

The results obtained in the present numerical model are validated with the experimental outcomes presented by Chandel et al. [9]. Furthermore, an analytical comparison of the results with that of Eulerian Langrage model using SST K- $\omega$ turbulence model has also been carried out. It is found that the simulated outcomes are in synchronism with the experimental one. However, one can clearly observe from Figs. 18 (a-c) that the pressure drops values obtained with Eulerian model using RNG K- $\varepsilon$ turbulence model are fairly accurate and more appropriate with that of SST K- $\omega$ turbulence model. The average percentage errors evaluated on the basis of deviation between simulated and experimental values for wide velocity ranges of 1-3 m/s are found to be $4.86 \%, 4.18 \%$ and $3.26 \%$ for solid concentrations of $50 \%, 60 \%$ and $70 \%$ respectively. Hence, the major contribution of the present study is the lower values of percentage errors ranging 3-5\% with RNG K- $\varepsilon$ turbulence model as compared to that of SST K- $\omega$ turbulence model.

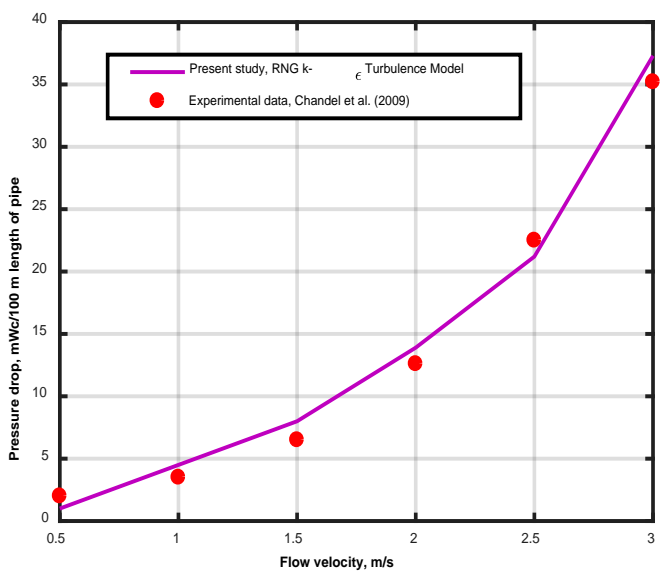

(a)

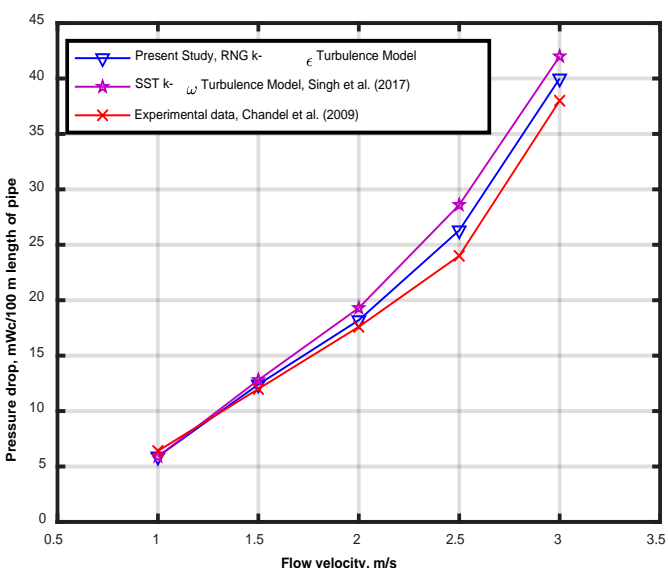

(b)

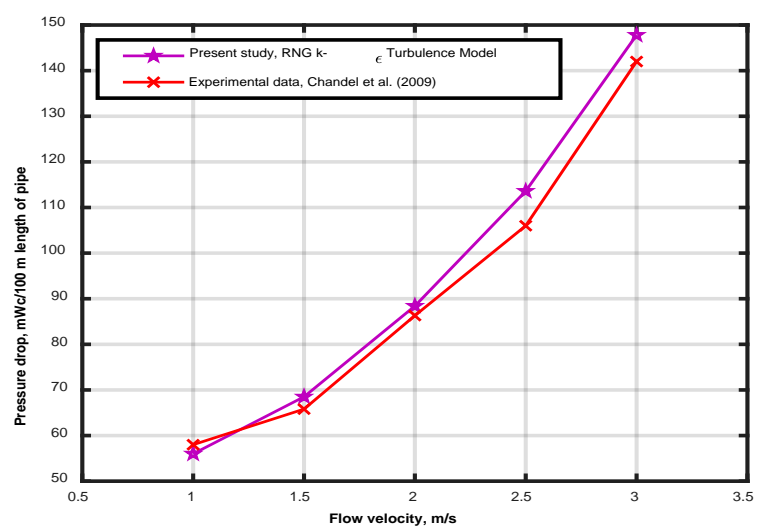

(c)

Figure 18. Validation of numerical simulation model at different values of (a) $C_{w}=50 \%$, (b) $C_{w}=60 \%$ and $\mathrm{C}_{\mathrm{w}}=70 \%$

\section{CONCLUSIONS}

Based on the investigations on $42 \mathrm{~mm}$ diameter ash-water slurry pipeline using commercial CFD software for different efflux concentrations and slurry velocities, the following conclusions have been drawn:

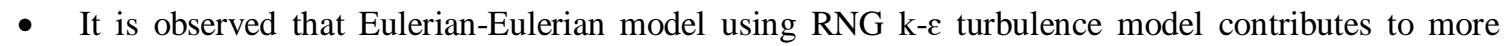
appropriate and meticulous predictions of the pressure drop for each chosen concentration and flow velocity.

- The distributions of fly ash concentrations are found to be asymmetric in nature in vertical direction under the flow conditions. The high fly ash concentration zone is observed on the lower part of the horizontal pipelines. 
- The vertical velocity profile has also been observed to be asymmetric in nature at low mean flow velocity and solid concentration. However, the asymmetric distribution shows diminution at high mean flow velocity and solid concentration due to increased turbulent mixing.

- At higher velocity and concentration, maximum fly ash elements shift towards the centre. Consequently, the high concentration zone is found here.

- Non-linear increase in pressure drop along with rise in slurry concentrations/velocities is observed.

- At high solid concentration and flow velocity, lateral disparities in solid levels are observed to be more dominant.

- The mean deviation between the projected and the real-time monitoring values of pressure drop is found to be in the range of $3-5 \%$ for various solid concentrations.

The obtained results of predetermined pressure drop are observed to be in synchronism with the experiment results. Moreover, the comparison of the simulated results with that of Eulerian-Langrange model using SST K- $\omega$ turbulence model proves the practical utility and high designing capability of Eulerian-Eulerian model with RNG $\mathrm{k}-\varepsilon$ turbulence model.

\section{NOMENCLATURE}

$\mathrm{CW} \quad$ Efflux concentration (by weight)

D Diameter of pipe (m)

$\mathrm{d}_{\mathrm{s}} \quad$ Particle diameter $(\mu \mathrm{m})$

G Acceleration due to gravity $\left(\mathrm{m} / \mathrm{s}^{2}\right)$

$\overrightarrow{v_{s}} \quad$ Velocity of solid phase $(\mathrm{m} / \mathrm{s})$

$\overrightarrow{v_{f}} \quad$ Velocity of fluid phase (m/s)

$\mathrm{C}_{\mathrm{vm}} \quad$ Coefficient of virtual mass

$\rho \quad$ Mass density $\left(\mathrm{kg} / \mathrm{m}^{3}\right)$

$\rho_{\mathrm{f}} \quad$ Mass density for fluid phase $\left(\mathrm{kg} / \mathrm{m}^{3}\right)$

$\rho_{\mathrm{s}} \quad$ Mass density for solid phase $\left(\mathrm{kg} / \mathrm{m}^{3}\right)$

$\mathrm{C}_{\mathrm{L}} \quad$ Lift force

$\mathrm{V}_{\mathrm{m}} \quad$ Mean flow velocity $(\mathrm{m} / \mathrm{s})$

$\mathrm{Re}_{\mathrm{s}} \quad$ Relative Reynold number between solid and fluid phase

$\overline{\bar{I}} \quad$ Identity tensor

$\lambda_{s} \quad$ Bulk viscosity of solid phase

$\overline{\overline{\tau_{f}}} \quad$ viscous stress tensor for fluid phase

$\mathrm{g}_{\mathrm{o}, \mathrm{ss}} \quad$ Radial distribution function

$\mu_{\mathrm{s}} \quad$ Shear viscosity for solid phase (Pa-s)

$\mu_{\mathrm{f}} \quad$ Shear viscosity for fluid phase (Pa-s)

$\mu_{\mathrm{s}, \mathrm{col}} \quad$ collisional viscosity

$\mu_{\mathrm{s}, k i n} \quad$ kinetic viscosity

$\mu_{\mathrm{s}, \mathrm{fr}} \quad$ frictional viscosity

$C_{D} \quad$ Drag coefficient

$\mathrm{e}_{\mathrm{ss}} \quad$ Restitution coefficient

$\Theta_{\mathrm{s}} \quad$ Granular temperature

$\mathrm{I}_{2 \mathrm{D}} \quad$ Second invariant strain rate tensor for solid phase

$\mathrm{K}_{\mathrm{sf}} \quad$ Inter-phasial momentum exchange coefficient

$\mathrm{V}_{\mathrm{r}, \mathrm{s}} \quad$ Terminal velocity for solid phase $(\mathrm{m} / \mathrm{s})$

Greek symbols

$\alpha_{\mathrm{s}, \max } \quad$ Static settled concentration,

$\alpha_{\mathrm{s}} \quad$ Solid phase concentration

$\alpha_{\mathrm{f}} \quad$ Liquid phase concentration 


\section{REFERENCES}

[1] Colwell JM, Shook CA. The entry length for slurries in horizontal pipeline flow. Can J Chem Eng 1988; 66(5): 714-720. doi:10.1002/cjce.5450660503.

[2] Turian RM, Hsu FL, Selim MS. Friction losses for flow of slurries in pipeline bends, fittings, and valves. Particul Sci Technol 1983; 1(4): 365-392. doi:10.1080/02726358308906383

[3] Matousek V. Pressure drops and flow patterns in sand-mixture pipes. Exp Therm Fluid Sci 2002; 26(6): 693-702. doi:10.1016/S0894-1777(02)00176-0.

[4] Krampa-Morlu FN, Bergstrom DJ, Bugg JD, Sanders RS, Schaan J. Numerical simulation of dense coarse particle slurry flows in a vertical pipe. In 5th Int Conf Multiphase flow, ICMF 2004; 4: 460.

[5] Kraft M. Modelling of Particulate Processes. KONA Powder Part J 2005; 23:18-35. doi:10.14356/kona.2005007.

[6] Kumar U, Singh SN, Seshadri V. Prediction of flow characteristics of bimodal slurry in horizontal pipe flow. Particul Sci Technol 2008; 26(4): 361-379. doi:10.1080/02726350802084564

[7] Lin CX, Ebadian MA. A numerical study of developing slurry flow in the entrance region of a horizontal pipe. Comput Fluids 2008; 37(8): 965-974. doi:10.1016/j.compfluid.2007.10.008.

[8] Chandel S, Singh SN, Seshadri V. Transportation of high concentration coal ash slurries through pipelines. Int Archive Appl Sci Tech 2010; 1: 1-9.

[9] Chandel S, Seshadri V, Singh SN. Effect of additive on pressure drop and rheological characteristics of fly ash slurry at high concentration. Particul Sci Technol 2009; 27(3): 271-284. doi: 10.1080/02726350902922036

[10] Naik HK, Mishra MK, Rao KU. Influence of chemical reagents on rheological properties of fly ashwater slurry at varying temperature environment. Coal Combus Gasification Products 2011; 3: 83-93.

[11] Senapati PK, Mishra BK, Parida BK. Analysis of friction mechanism and homogeneity of suspended load for high concentration fly ash \& bottom ash mixture slurry using rheological and pipeline experimental data. Powder Technol 2013; 250: 154-163. doi: 10.1016/j.powtec.2013.10.014.

[12] Jiang YY, Zhang P. Numerical investigation of slush nitrogen flow in a horizontal pipe. Chem Eng Sci 2012; 73: 169-180. doi:10.1016/j.ces.2012.01.027.

[13] Kaushal DR, Thinglas T, Tomita Y, Kuchii S, Tsukamoto H. CFD modeling for pipeline flow of fine particles at high concentration. Int J Multiphas Flow 2012; 43: 85-100. doi: 10.1016/j.ijmultiphaseflow.2012.03.005.

[14] Kaushal DR, Kumar A, Tomita Y, Kuchii S, Tsukamoto H. Flow of mono-dispersed particles through horizontal bend. Int J Multiphas Flow 2013; 52: 71-91. doi:10.1016/j.ijmultiphaseflow.2012.12.009

[15] Nabil T, El-Sawaf I, El-Nahhas K. Sand-Water Slurry Flow Modelling in a Horizontal Pipeline by Computational fluid Dynamics Technique. Int Water Tech J 2014; 4(1): 13.

[16] Silva R, Garcia FAP, Faia Pedro MGM, Rasteiro M.G. Settling suspensions flow modelling: A review. KONA Powder Part J 2015; 32: 41-56. doi: 10.14356/kona.2015009.

[17] Gopaliya MK, Kaushal DR. Analysis of effect of grain size on various parameters of slurry flow through pipeline using CFD. Particul Sci Technol 2015; 33(4): 369-384. doi:10.1080/02726351.2014.971988

[18] Pani GK, Rath P, Barik R, Senapati PK. The effect of selective additives on the rheological behavior of power plant ash slurry. Particul Sci Technol 2015; 33(4): 418-422. doi:10.1080/02726351.2014.990657

[19] Assefa KM, Kaushal DR. Experimental study on the rheological behaviour of coal ash slurries. J Hydrol Hydromech 2015; 63(4): 303-310.

[20] Swamy M, Díez NG, Twerda A. Numerical modelling of the slurry flow in pipelines and prediction of flow regimes. WIT Trans Eng Sci 2015; 89: 311-322.

[21] Wu D, Yang B, Liu Y. Pressure drop in loop pipe flow of fresh cemented coal gangue-fly ash slurry: Experiment and simulation. Adv Powder Technol 2015; 26(3): 920-927. doi:10.1016/j.apt.2015.03.009.

[22] Messa GV, Malavasi S. Improvements in the numerical prediction of fully-suspended slurry flow in horizontal pipes. Powder Technol 2015; 270: 358-367. doi:10.1016/j.powtec.2014.02.005.

[23] Gopaliya MK, Kaushal DR. Modeling of sand-water slurry flow through horizontal pipe using CFD. J Hydrol Hydromech 2016; 64(3): 261-272.

[24] Ofei TN, Ismail AY. Eulerian-Eulerian simulation of particle-liquid slurry flow in horizontal pipe. J Pet Eng 2016; 1-10. doi:10.1155/2016/5743471. 
[25] Peng W, Cao X. Numerical simulation of solid particle erosion in pipe bends for liquid-solid flow. Powder Technol 2016; 294: 266-279. doi:10.1016/j.powtec.2016.02.030.

[26] Kaushal DR, Kumar A, Tomita Y, Kuchii S, Tsukamoto H. Flow of Bi-modal Slurry through Horizontal Bend. KONA Powder Part J 2017; 34: 258-274. doi:10.14356/kona.2017016.

[27] Assefa, KM, Kaushal DR. A new model for the viscosity of highly concentrated multi-sized particulate Bingham slurries. Particul Sci Technol 2017; 35(1): 77-85. doi:10.1080/02726351.2015.1131789.

[28] Melorie, AK, Kaushal DR. Experimental investigations of the effect of chemical additives on the rheological properties of highly concentrated iron ore slurries. KONA Powder Part J 2017; 2018001. doi:10.14356/kona.2018001.

[29] Naveh R, Tripathi NM, Kalman H. Experimental pressure drop analysis for horizontal dilute phase particle-fluid flows, Powder Technol 2017; 321: 355-368. doi:10.1016/j.powtec.2017.08.029.

[30] Singh JP, Kumar S, Mohapatra SK. Modelling of two-phase solid-liquid flow in horizontal pipe using computational fluid dynamics technique. Int J Hydrogen Energy 2017; 42(31): 20133-20137. doi:10.1016/j.ijhydene.2017.06.060

[31] Arora R, Kaushik SC, Kumar Raj, Arora R. Soft computing based multi-objective optimization of Brayton cycle power plant with isothermal heat addition using evolutionary algorithm and decision making. Appl Soft Comput 2016; 46: 267-283. doi:10.1016/j.asoc.2016.05.001.

[32] Kumar R, Kaushik SC, Kumar Raj, Hans R. Multi-objective thermodynamic optimization of irreversible regenerative Brayton cycle using evolutionary algorithm and decision making. Ain Shams Eng J 2016; 7 (2): 741-753. doi:10.1016/j.asej.2015.06.007.

[33] Arora R, Kaushik SC, Kumar R. Multi-objective thermodynamic optimization of solar parabolic dish Stirling heat engine with regenerative losses using NSGA-II and decision making. Appl Sol Energ 2016; 52 (4): 295-304. doi:10.3103/S0003701X16040046.

[34] Arora R, Kaushik SC, Kumar R, Arora R. Multi-objective thermo-economic optimization of solar parabolic dish Stirling heat engine with regenerative losses using NSGA-II and decision making. Int J Elec Power 2016; 74: 25-35. doi:10.1016/j.ijepes.2015.07.010.

[35] Shirvan KM, Ellahi R, Mamourian M, Moghiman M. Effect of wavy surface characteristics on heat transfer in a wavy square cavity filled with nanofluid. Int J Heat Mass Tran 2017; 107: 1110-1118. doi:10.1016/j.ijheatmasstransfer.2016.11.022.

[36] Ellahi R, Tariq MH, Hassan M, Vafai K. On boundary layer magnetic flow of nano-ferroliquid under the influence of low oscillating over stretchable rotating disk. J Mol Liq 2017; 229: 339-345. doi:10.1016/j.molliq.2016.12.073.

[37] Esfahani JA, Akbarzadeh M, Rashidi S, Rosen MA, Ellahi R. Influences of wavy wall and nanoparticles on entropy generation in a plate heat exchanger. Int J Heat Mass Tran 2017; 109: 1162-1171. doi:10.1016/j.ijheatmasstransfer.2017.03.006.

[38] Hassan M, Zeeshan A, Majeed A, Ellahi R. Particle shape effects on ferrofuids flow and heat transfer under influence of low oscillating magnetic field. J Magn Magn Mater 2017; 443: 36-44. doi:10.1016/j.jmmm.2017.07.024.

[39] Rashidi S, Akar S, Bovand M, Ellahi R. Volume of fluid model to simulate the nanofluid flow and entropy generation in a single slope solar still. Renew Energ 2018; 115: 400-410. doi:10.1016/j.renene.2017.08.059

[40] Ijaz N, Zeehan A, Bhatti MM, Ellahi R. Analytical study on liquid-solid particles interaction in the presence of heat and mass transfer through a wavy channel. J Mol Liq 2018; 250: 80-87. doi:10.1016/j.molliq.2017.11.123.

[41] Zeeshan A, Shehzad N, Ellahi R. Analysis of activation energy in Couette-Poiseuille flow of nanofluid in the presence of chemical reaction and convective boundary conditions. Results Phys 2018; 8: 502512. doi:10.1016/j.rinp.2017.12.024.

[42] Ellahi, R. Special Issue on Recent Developments of Nanofluids. Appl Sci 2018; 8: 192. doi:10.3390/app8020192.

[43] Ghadikolaei SS, Hosseinzadeh Kh, Ganji DD. Analysis of unsteady MHD Eyring-Powell squeezing flow in stretching channel with considering thermal radiation and Joule heating effect. Case Studies in Thermal Engineering 2017; 10: 579-594. doi:10.1016/j.csite.2017.11.004 
[44] Ghadikolaei SS, Hosseinzadeh Kh, Ganji DD, Hatami M. $\mathrm{Fe}_{3} \mathrm{O}_{4}-\left(\mathrm{CH}_{2} \mathrm{OH}\right)_{2}$ nanofluid analysis in a porous medium under MHD radiative boundary layer and dusty fluid. J Mol Liq 2018; 258: 172-185. doi:10.1016/j.molliq.2018.02.106

[45] Arora R, Arora R. Multiobjective optimization and analytical comparison of single- and 2-stage (series/parallel) thermoelectric heat pumps. Int J Energ Res 2018; 42 (4): 1760-1778. doi:10.1002/er.3988.

[46] Ghadikolaei SS, Yassari M, Sadeghi H, Hosseinzadeh Kh, Ganji DD. Investigation on thermophysical properties of $\mathrm{TiO}_{2}-\mathrm{Cu} / \mathrm{H}_{2} \mathrm{O}$ hybrid nanofluid transport dependent on shape factor in MHD stagnation point flow. Powder Technol 2017; 322: 428-438. doi:10.1016/j.powtec.2017.09.006.

[47] Ghadikolaei SS, Hosseinzadeh Kh, Yassari M, Sadeghi H, Ganji DD. Boundary layer analysis of micropolar dusty fluid with $\mathrm{TiO}_{2}$ nanoparticles in a porous medium under the effect of magnetic field and thermal radiation over a stretching sheet. J Mol Liq 2017; 244: 374-389. doi:10.1016/j.molliq.2017.08.111

[48] Hosseinzadeh Kh, Amiri AJ, Ardahaie SS, Ganji DD. Effect of variable lorentz forces on nanofluid flow in movable parallel plates utilizing analytical method. Case Studies in Thermal Engineering 2017; 10: 595-610. doi:10.1016/j.csite.2017.11.001

[49] Arora R, Arora R. Multicriteria optimization based comprehensive comparative analyses of single- and two-stage (series/parallel) thermoelectric generators including the influence of Thomson effect. J Renew Sustain Ener 2018; 10 (4): 044701.doi:10.1063/1.5019972.

[50] Arora R, Arora R. Performance Characteristics and Thermodynamic Investigations on Single-Stage Thermoelectric Generator and Heat Pump Systems. Pertanika J Sci Technol 2018; 26 (4): 1975-1998.

[51] Hosseinzadeh Kh, Alizadeh M, Ganji DD. Hydrothermal analysis on MHD squeezing nanofluid flow in parallel plates by analytical method. International Journal of Mechanical and Materials Engineering 2018; 13:4. doi:10.1186/s40712-018-0089-7.

[52] Kumar R, Kaushik SC, Kumar R. Power optimization of an Irreversible regenerative Brayton Cycle using isothermal heat addition. J Therm Eng 2015; 1(4): 279-286. doi:10.18186/jte.44164.

[53] Kaushik SC, Kumar R, Arora R. Thermo-economic optimization and parameteric study of an irreversible Brayton heat engine cycle. J Therm Eng 2016; 2 (4): 861-870.

[54] Arora R, Kaushik SC, Kumar R. Performance optimization of Brayton heat engine at maximum efficient power using temp. dependent specific heat of working fluid. J Therm Eng 2015; 1 (2): 345-354. doi:10.18186/jte.15036.

[55] Arora R, Kaushik SC, Kumar R. Multi-objective optimization of an irreversible regenerative Brayton cycle using genetic algorithm. In 2015 Int Conf on Futuristic Trends on Computational Analysis and Knowledge Management (ABLAZE), IEEE 2015; 340-346. doi: 10.1109/ABLAZE.2015.7155017.

[56] Arora R, Kaushik SC, Kumar R. Multi-objective optimization of solar powered ericsson cycle using genetic algorithm and fuzzy decision making. In 2015 Int Conf on Advances in Computer Engineering and Applications (ICACEA), IEEE 2015; 553-558. doi:10.1109/ICACEA.2015.7164754.

[57] Arora R, Kaushik SC, Kumar R. Multi-objective thermodynamic optimisation of solar parabolic dish Stirling heat engine using NSGA-II and decision making. International Journal of Renewable Energy Technology 2017; 8 (1): 64-92. doi:10.1504/IJRET.2017.080873.

[58] Kumar Rajesh, Kaushik SC, Kumar Raj. Performance Analysis of an Irreversible Regenerative Brayton Cycle based on Ecological Optimization Criterion. International Journal of Thermal and Environment Engineering 2015; 9(1): 25-32.

[59] Kumar R, Kaushik SC, Kumar R. Efficient power of Brayton heat engine with friction. International Journal of Engineering Research and Technology 2013; 6 (5): 643-650.

[60] Arora R, Kaushik SC, Arora R. Multi-objective and multi-parameter optimization of two-stage thermoelectric generator in electrically series and parallel configurations through NSGA-II. Energy 2015; 91: 242-254. doi:10.1016/j.energy.2015.08.044

[61] Arora R, Kaushik SC, Arora R. Thermodynamic modeling and multi-objective optimization of two-stage thermoelectric generator in electrically series and parallel configurations. Appl Therm Eng 2016; 25 (103): 1312-1323. doi:10.1016/j.applthermaleng.2016.05.009. 
[62] Arora R, Arora R. Experimental Investigations and Exergetic Assessment of $1 \mathrm{~kW}$ Solar PV Plant. Pertanika J Sci Technol 2018; 26 (4): 1881-1897.

[63] Arora R, Arora R, Sridhara SN. Performance assessment of $186 \mathrm{kWp}$ grid interactive solar photovoltaic plant in Northern India. Int. J. Ambient Energy 2019; 1-28. doi:10.1080/01430750.2019.1630312

[64] Ahmed SU, Arora R. Quality characteristics optimization in CNC end milling of A36 K02600 using Taguchi's approach coupled with artificial neural network and genetic algorithm. International Journal of System Assurance Engineering and Management 2019; 10(4):676-95. doi:10.1007/s13198-01900796-8.

[65] Chiteka K, Arora R, Jain V. CFD Prediction of dust deposition and installation parametric optimisation for soiling mitigation in non-tracking solar PV modules. Int. J. Ambient Energy 2019; 5:1-14. doi:10.1 080/01430750.2019.1594373.

[66] Mohanty S, Arora R, Parkash O. Performance prediction and comparative analysis for a designed, deve loped, and modeled counterflow heat exchanger using computational fluid dynamics. Computational Thermal Sciences: An International Journal 2019; 11(5): 423-443. doi:10.1615/ComputThermalScien.2 019028520.

[67] Arora R, Arora R. Parametric Investigations and Thermodynamic Optimization of Regenerative Brayton Heat Engine. In Advances in Fluid and Thermal Engineering 2019; 753-762. Springer, Singapore. doi:10.1007/978-981-13-6416-7_70.

[68] Parkash O, Kumar A, Sikarwar BS. CFD Modeling of Commercial Slurry Flow Through Horizontal Pipeline. In Advances in Interdisciplinary Engineering 2019; 153-162. Springer, Singapore. doi:10.1007/978-981-13-6577-5_16.

[69] Maputi ES, Arora R. Design optimization of a three-stage transmission using advanced optimization techniques. International Journal for Simulation and Multidisciplinary Design Optimization 2019;10: A8. doi:10.1051/smdo/2019009.

[70] Maputi ES, Arora R. Multi-objective spur gear design using teaching learning-based optimization and decision-making techniques. Cogent Engineering 2019; 6(1):1665396. DOI: $10.1080 / 23311916.2019 .1665396$

[71] Chiteka K, Sridhara SN, Arora R. Numerical investigation of installation and environmental parameters on soiling of roof-mounted solar photovoltaic array. Cogent Engineering 2019;6(1):1649007. DOI: $10.1080 / 23311916.2019 .1649007$

[72] Chiteka K, Arora R, Sridhara SN. A method to predict solar photovoltaic soiling using artificial neural networks and multiple linear regression models. Energ Syst 2019; 1-22. doi:10.1007/s12667-019-00348-w. 